This item was submitted to Loughborough's Research Repository by the author.

Items in Figshare are protected by copyright, with all rights reserved, unless otherwise indicated.

\title{
Variability in the use of mobile ICTs by homeworkers and its consequences for boundary management and social isolation
}

\section{PLEASE CITE THE PUBLISHED VERSION}

http://dx.doi.org/10.1016/j.infoandorg.2015.10.001

\section{PUBLISHER}

(C) Elsevier Ltd.

\section{VERSION}

AM (Accepted Manuscript)

\section{PUBLISHER STATEMENT}

This work is made available according to the conditions of the Creative Commons Attribution-NonCommercialNoDerivatives 4.0 International (CC BY-NC-ND 4.0) licence. Full details of this licence are available at: https://creativecommons.org/licenses/by-nc-nd/4.0/

\section{LICENCE}

CC BY-NC-ND 4.0

\section{REPOSITORY RECORD}

Hislop, Donald, Carolyn Axtell, Alison Collins, Kevin Daniels, Jane Glover, and Karen Niven. 2015. "Variability in the Use of Mobile Icts by Homeworkers and Its Consequences for Boundary Management and Social Isolation". Loughborough University. https://hdl.handle.net/2134/19542. 


\title{
Variability in the Use of Mobile ICTs by Homeworkers and its Consequences for Boundary Management and Social Isolation
}

\author{
$\underline{\text { Abstract }}$ \\ We examine how the use of mobile information and communication technologies \\ (ICTs) among self-employed homeworkers affects their experience of work, \\ focussing particularly on where work is carried out, how the work/non-work \\ boundary is managed, and people's experiences of social and professional isolation. \\ Positively, their use enhanced people's sense of spatio-temporal freedom by \\ allowing them to leave the home without compromising their work availability. This \\ also helped reduce people's feelings of social isolation. More negatively their use \\ enhanced people's sense of 'perpetual contact', creating a sense that work was \\ difficult to escape from. However, the extent to which mobile ICTs were used, and \\ the extent to which their impact on people's experiences of work were understood, \\ were found to vary significantly, highlighting the agency that users have with regard \\ to technology use. The findings are framed by combining Nippert-Eng's boundary \\ work theory, with an 'emergent process' perspective on socio-technical relations.
}

Keywords: homeworking, mobile ICTs, telework, work/non-work boundary, social isolation 


\section{Introduction}

The work-related use of contemporary mobile and wireless information and communication technologies (ICTs) is a topic that has received much attention in recent years. Many writers suggest their impact on the nature and experience of work has been significant. For example, Matusik \& Mickel (2012, p. 1002) suggest that mobile ICTs are 'revolutionizing when, where, how, and how long employees work'. However, this represents a relatively embryonic topic area and many gaps in knowledge exist. Thus, while there has been some research on the work-related use of mobile phones and other types of mobile ICTs such as personal digital assistants (PDAs), this has typically focussed narrowly on office-based professionals (see for example, Richardson \& Benbunan-Fich 2011, Tennakoon et al 2013). Very few studies have considered the use of these technologies by home-based workers. One of the main themes of the research on mobile ICT use is the flowing of work into the non-work and home domain (Derks \& Bakker 2012, Fenner \& Renn 2010, Golden \& Geisler 2007, Orlikowski 2007, Richardson \& Benbunan-Fich 2011, Sarker et al 2012). The use of mobile ICTs for people whose home represents their primary workplace therefore raises interesting questions about how the use of these technologies affects the experience of work, and the character of the work/nonwork boundary. This paper contributes to knowledge by examining this topic.

In examining home-based workers, the specific focus here is on the ways in which mobile ICT use affects their spatio-temporal flexibility, with a particular emphasis on how mobile ICT use affects where work is and can be done. Building from the assumption that, 'where work is done makes a difference for working practices and to organizational and personal relationships' (Halford 2005, p. 20), the paper also considers how mobile ICT use impacts on how the work/non-work boundary is managed, as well as people's experiences of social isolation while working. 
The paper makes linkages between the literatures on the work-related use of mobile ICTs and homeworking, and in doing so contributes to both. Conceptually, the paper contributes to knowledge by linking together an 'emergent process' perspective on technology (Orlikowski 2010) with Nippert-Eng's (1996) boundary work theory, both of which focus on the agency of actors operating within the constraints of their particular personal and work circumstances. It does this fundamentally through examining how some self-employed homeworkers use of mobile ICTs affected their work experience, a topic not examined to any great extent in either literature. The paper makes a further contribution to the homeworking literature by examining a neglected type of homeworker, those who are self-employed. Despite the heterogeneity in the character of homeworkers that exists (in terms of factors such as employment status and occupation), the academic literature on this topic has tended to focus narrowly on managerial and professional workers who are employees (Tietze et al 2009).

The paper begins by reviewing relevant literature on the use of mobile ICTs, with a particular focus on how their use affects the way people manage the work/nonwork boundary and experience isolation. This section concludes by highlighting gaps in the literature with regard to home-based workers, and summarizing the research questions examined. Following this, the methods used for identifying and selecting research participants, and the collection and analysis of data are outlined. The paper's empirical findings are then presented, through using relevant interview quotes to highlight participant's views and experiences. Finally, the paper concludes with an extended discussion.

2. The Experience of Homeworking: Work-life Balance, Boundary Management and Isolation

Before proceeding any further, it is useful to clarify the terminology being used to describe the workers examined here. One feature of the literature on 
teleworking/homeworking is the diversity of labels that are utilized (Tietze et al 2009). For the workers examined here their homes constitute their primary workplace, but they do make extensive use of ICTs in carrying out their work. Thus, the workers examined here are referred to as (self-employed) technologydependent homeworkers.

As one of the central foci of the paper is on how homeworkers' use of mobile ICTs affected their experience of work, it is useful to begin this literature review by outlining the perspective on technology-human relations utilized here. A key reason why it is necessary to do this is the diversity of perspectives on this topic that exist. A useful paper in this respect is Orlikowski's (2010) review paper. We adopt what Orlikowski labels the 'emergent process' perspective, which is based on an 'ontology of separateness', which regards technological artefacts and human action as separable and ontologically distinct. The 'emergent process' perspective is sensitive to the socially constructed nature of technology, taking active account of the role played by technology designers and users in shaping how technologies are used and evolve. In doing so, this perspective takes account both of how people understand and make sense of technology and how they use it. A key feature of this perspective is a central focus on the role played by human agency in shaping technology use. This perspective is utilized here as the key empirical focus during data collection was on how homeworkers made sense of and utilized mobile ICTs in carrying out their work, with limited attention being devoted to the micro-level detail of how the materiality of these artefacts also shaped how they were used.

The two central aspects of homeworkers' work experience that are examined here relate to (i) issues of work-life balance, and the character of the boundary between the domains of work and non-work, and (ii) issues of social and professional isolation. Both topics have been identified as being important features in the academic literature on homeworker's work experiences (see below), and homeworker's experiences in both domains have been affected by changes and developments in ICTs. 
2.1 Work-life balance and the Management of the work-life Boundary

Although one of the articulated advantages of homeworking is that it improves people's ability to achieve a satisfactory work-life balance (see for example Baruch 2001), empirical research findings on this topic are somewhat ambiguous. On the plus side, the autonomy and temporal flexibility provided by homeworking typically produces a positive work-life balance impact, giving people the scope to synchronize work and non-work schedules and commitments (Maruyama et al 2006). However, more negatively, the fact that work is carried out in the home means that the boundary between the domains of work and non-work can become blurred, which can increase the occurrence of work/non-work conflict and mean that homeworkers find it difficult to 'switch off' from work (Maruyama et al 2006, Tietze \& Musson 2005, Tietze et al 2009).

In examining the topic of the work/non-work boundary, it is useful to link to the influential work of Nippert-Eng (1996) who developed the theory of 'boundary work' to make sense of how people manage this boundary. The segmentationintegration boundary preference spectrum she developed represents a key aspect of boundary theory. This argues that people's preferences regarding the character of the work-non-work boundary exist on a spectrum between the extremes of segmentors, who like to keep these domains totally separate, and integrators, who do not distinguish between the domains, and who are happy to have them continually blended together. Central to boundary theory is the agency of individuals, who continually shape and manage this boundary on a day-to-day basis, with their activity in turn shaped and constrained by the specific character of their home and work domains. Thus, this focus on human agency links well with the 'emergent process' perspective on technology-human relations adopted. Further, by taking account of the specific character of people's work and home domains, it allows full account to be taken of how the self-employed status of the interviewees in this study shaped their boundary management activities. In taking account of 
such contextual factors Nippert-Eng's analysis also highlights the distinctive and heterogeneous character of people's boundary management activities, which are shaped by their individual work and life circumstances, and personal preferences. This is illustrated by Nansen's et al's (2010) into the home-based boundary management practices of four Australian families where at least one member conducted some paid employment from home. Rather than identify particular common, dominant strategies for boundary management, Nansen et al found significant variance, with a diversity of specific boundary management strategies related to the use of space, time and technology being used in each home.

Nippert-Eng (1996) argues that people's boundary management activities and preferences typically evolve over time, as their personal and work circumstances change. Contemporary developments in mobile ICTs represent one such change that is likely to affect the work experience of technology-dependent homeworkers. Firstly, there are potentially significant spatio-temporal implications, with these devices facilitating anytime, anywhere communication. Secondly, and relatedly, these devices have potentially contradictory consequences for how people manage the work/non-work boundary. Positively, their functionality means they provide a potential means to manage the work/non-work boundary (Cousins \& Robey 2005, Golden \& Geisler 2007, Kreiner et al 2009, Tennakoon et al 2013). However, more negatively, their use can simultaneously blur the work/non-work boundary, and provide scope for work to increasingly encroach on non-work time meaning that workers can feel a sense of 'constant connectivity' whereby they are never able to fully escape the demands of work (Barley et al 2011, MacCormick et al 2012, Duxbury et al 2014, Matusick \& Mickel 2011, Sarker et al 2012). One aspect of these developments is that work can increasingly intrude into the home domain. For example, Duxbury et al's (2014) longitudinal, qualitative study of Blackberry use by 25 office-based knowledge workers from one Canadian organization found the majority (13 people), labelled 'struggling segmentors', found that Blackberry use made it difficult to disconnect from work when at home, away from the office, and 
that as a consequence they experienced an increased level of work/family conflict. Of the other 12 workers examined, 8 were classified as 'segmentors', who were successful in using their Blackerries while still being able to maintain a clear separation between work and non-work domains, while the remaining four were 'integrators', who found Blackberry use helped them in synchronizing the demands of work and non-work domains. In general terms, the technical characteristics of mobile ICTs appear most compatible with integration-based boundary management strategies (Richardson \& Benbunan-Fich 2011). However, it is important to also highlight that the blurring of the work/non work boundary is not an inevitable consequence of mobile ICT use, as users of these technologies have a significant degree of agency to shape the nature of this boundary (Cousins \& Robey 2005, Golden \& Geisler 2007, Wajcman et al 2008)

A final aspect of work-related mobile ICT use identified by a number of analysts is their paradoxical character, which has potential implications for how people manage the work/non-work boundary. This has been most recently discussed by Mazmanian et al (2013) based on a study of Blackberry use by knowledge professionals in the USA. Fundamentally, Mazmanian et al found that technology use practices that people perceived as providing autonomy, the ability to work anytime, anywhere, ultimately resulted in the unintended consequence of them experiencing reduced levels of autonomy, through feeling an increasing need to work all the time/everywhere. These reduced levels of autonomy resulted in work increasingly intruding into people's non-work domain, as people increasingly felt compelled to monitor and respond to work-related communications all the time. The paradoxical character of mobile ICT use is an issue also discussed by both Arnold (2003) and Jarvenpaa \& Lang (2005). Arnold (2003, p. 233) defines a paradox as, 'a selfreferential statement in two parts ... [which] in combination, is irreconcilable'. In applying the paradox concept to understand mobile phone use, Arnold identifies a number of paired factors that are contradictory but which apply simultaneously (such as private/public, independent/co-dependent, production/consumption).The pairing most relevant to the consequences of mobile ICT use considered here is the 
mobile/fixed (liberated/leashed) pairing. With this pairing, mobile ICT use simultaneously produces a sense of mobility and fixity. It generates a sense of spatial mobility and temporal flexibility, as mobile ICTs allow people to use them from anywhere (signal permitting). Thus mobile ICT use facilitates substantially more mobility than using fixed phone lines, desktop computers, or even laptop computers does. However, simultaneously mobile ICT use creates a sense of fixity and permanence, as to operate as effective mobile device people need specific phone numbers and email addresses for other people to use. Thus mobile ICT users have fixed contact details that can be used by others to contact them irrespective of time or location. Further, once people know this (unchanging) information it makes it possible for them to contact people anywhere, regardless of time and space. Thus, in this sense, the use of mobile ICTs simultaneously creates a sense of spatio-temporal 'liberation', while users also experience a sense of being 'leashed' to their mobile ICT artefact (phone, PDA etc).

To date, most studies in this area have focussed on office based-workers, examining how for those who are mobile or office-based, work is increasingly intruding into the home domain. Little attention has thus been devoted to how mobile ICT use by homeworkers has affected the nature of their work/non-work boundary or experience of work more generally. One of the only studies to consider this issue is that of Lal and Dwivendi (2010), who examined whether mobile phone use by homeworkers allowed them to be available for work 'anytime, anywhere'. They found that despite people using their mobile phones to be available for work outside of their formal work hours this did not result in them developing an 'anytime, anywhere' mentality due to various actions they took to limit the extent to which they used their mobile phones outside of work hours. However, the insights provided by this paper are limited by the fact that few details are given either on the type of workers examined, or the reasons why they use mobile phones for their work. A later article by Mustafa and Gold (2013) presented the analysis of a diary and interview-based study of some self-employed teleworkers. In relation to the impact of mobile technology use on people's experiences of work, Mustafa and Gold 
found that mobile ICTs broadly had a negative impact, meaning that the people studied did feel a sense of 'perpetual contact' having a sense of being 'chained' to their work and feeling that they were never able to escape the demands of their clients. Thus, knowledge of how mobile ICT use is affecting the experience of homeworkers is very limited. The present paper adds to knowledge in this area. Moreover, it broadens our understanding of the 'home' domain by considering how time spent outside of the home domain may play a role in how the boundary between work and non-work is managed.

\subsection{Social isolation}

One of the articulated potential disadvantages of homeworking is that the more time people spend working at home the greater their sense of social and professional isolation becomes, through the limited opportunities that working at home provides for formal and informal interaction with colleagues, peers and managers (Mann \& Holdsworth 2003). A number of studies have produced findings on this topic. Firstly, Cooper and Kurland (2002) examined professional isolation, defined as having limited access to development opportunities, promotion and reward. They found that homeworking did result in a sense of professional isolation, due to people losing out on informal opportunities for learning and communication. Further, they found that this relationship was stronger in private sector organizations than it was in public sector organizations. Secondly, Morganson et al (2010) reached a similar conclusion in their comparison of various aspects of the work experience of people working at four different types of location (main employer office, satellite office, client site, and home). One issue they examined was people's perceived level of workplace inclusion/exclusion, which was argued to be a parallel concept to professional isolation. Inclusion was defined as having a sense of belonging, feeling invited to participate in significant decision making, and perceiving that your opinions matter. Homeworkers were found to have a noticeably lower sense of inclusion than office-based workers and thus, had a greater sense of professional isolation. Thirdly, Golden et al (2008) found that the 
sense of isolation homeworkers experienced was directly and positively related to the amount of time they spent working at home. Finally, somewhat in contradiction to the above findings, Halford's (2005) qualitative case study of workers in one organization who changed from being purely office-based to being part-time homeworkers did not find that they felt socially isolated after this transition. This was because they were able to socialize and interact with colleagues electronically when they worked at home, and face-to-face when they worked in the office.

One limitation of these studies, in relation to the focus here on self-employed homeworkers, was that these studies were all of employees who worked for reasonably sized organizations, with the employees studied typically having a number of colleagues who either also worked at home, or in their employer's offices. Thus, their experience of professional and social interaction with colleagues is likely to have limited comparability to the case of self-employed home workers, who do not have any employed colleagues to communicate with at all. Thus, the lack of colleagues possessed by self-employed homeworkers may mean they are more likely to experience a sense of social and professional isolation than employed homeworkers.

\subsection{The present research}

The focus here is on examining the extent to which, and ways in which, the use of mobile ICTs such as smartphones affected two key features of the experience of work of some self-employed homeworkers: how they managed the work/non-work boundary; and how it affected their experience of social and professional isolation.. Following Nippert-Eng (1996), we assume that the particular character of people's work context will impact on their ability to manage the work/non-work boundary. In this respect, the work context of self-employed homeworkers is likely to be quite different from that of office-based employees. While some research has been done on both topics, the experience of self-employed, homeworkers has been neglected. Our paper contributes to knowledge by examining how work-related mobile ICT use affected both these aspects of work, for this neglected type of worker. 


\section{Research Methods}

\subsection{Sample}

The data presented here is part of a wider study investigating issues of stress and wellbeing among self-employed homeworkers. In order to have a research population whose experiences were similar and comparable, we decided to select research participants doing similar types of work. Potential participants were identified by a process of opportunistic sampling through contacts possessed by one of the paper's authors. The majority of these contacts undertook IT-based office support/administrative work. A decision was therefore taken to focus the research purely on people undertaking such work. In summary, the three criteria sought from participants were that they were home-based workers, were self-employed, and undertook IT based office/administrative support work. A sample of fourteen people agreed to participate in the research.

Each participant was an administrator who provided remote administrative support to one or more clients. Almost all of their work was carried out at their homes and the type of administrative support they provided included a variety of tasks such as book keeping, typing, management of client websites and social media and marketing support. They are characterized as technology-dependent workers as not only were the work tasks they carried out largely computer-based, but interactions with clients were also typically ICT mediated.

A key feature of the interviewees' work context, which shaped their experience of work, was that they were self-employed. Their employment status as self-employed shaped their experience of work significantly. Firstly, they were responsible for both obtaining work from potential clients, and also managing their own time and workload to ensure that they were able to deliver work to clients within the 
timescales that had been promised. While some of the homeworkers researched worked for a range of clients, most were quite dependent upon a relatively small number of clients for the majority of their work (on average between two and five clients). The typically small number of clients that people worked for, combined with the need to directly communicate with clients to obtain work and continue their business, typically meant that the homeworkers interviewed felt dependent upon their clients, and regarded it as important to provide them with a good quality service. Secondly, as self-employed homeworkers they had no colleagues who they could interact with socially or professionally.

Participants devoted different amounts of time to their virtual administration work, details of which are provided in Table 1. The amount of time people devoted to their virtual administration business was categorized into three types: full time, where people did this work on average more than 30 hours per week, part time, where they did this work for between 20-29 hours per week, and half time, where they did this work for less than 20 hours per week. As Table 1 shows, almost half of the interview cohort worked full time (seven people), while the remaining half of interviewees worked either part time (four people) or half time (three people). Background details are provided on employees personal and domestic circumstances. This can be summarized as follows: all interviewees were female, with most typically aged in their 40 s, with the vast majority (11 out of 14 ) living with their spouse, and with half having one or two children (varying in age from under 5 , to adult).

\section{Insert Table 1 about here}

\subsection{Data Collection Procedure}

Data was collected from participants via telephone interviews which typically lasted about 45 minutes, with all conversations being digitally recorded with participants' consent. The interviews were qualitative conversations, being focussed around a 
standard list of open-ended questions that were asked to all interviewees. The key topics discussed in the interviews included the nature of people's work, their feelings about their work, the positive and negative features of their work, the extent to which work was a source of stress or fatigue, how work-related stress/fatigue was dealt with, as well as the role of ICTs and mobile ICTs in their work and the management of the work-life boundary. For this paper, the focus is narrowly on the interview data related to people's feelings about and experiences of work, and the way in which they used ICTs in carrying out their work.

\subsection{Data Analysis}

The analytical methodology utilized was what Berg (2006) characterizes as qualitative content analysis, with the objective being to identify patterns in the interview data. This was done in two stages. Firstly, the initial stage of coding was undertaken to provide an overview of the general themes in the data. This process was undertaken by two authors separately. At this stage, coding was done at one level only, to identify the key themes in the interviews. One theme which emerged from this coding process was the use of mobile ICTs and how this changed the nature and experience of people's work. Once a decision had been taken by all authors to explore this theme in detail the second stage of coding began. This involve a more fine grained process of coding which focussed on and drilled down into this theme to investigate patterns of mobile ICT usage among interviewees. This process was led by the paper's lead author, with all other authors being involved in refining and commenting upon this analysis.

\section{$\underline{\text { 5. Findings }}$}

This section of the paper is organized into two parts. The first section outlines what were identified by interviewees as being significant aspects of being a selfemployed, technology-dependent homeworker, which is done via examining what were identified as the most positive and negative features of this type of work. The 
second section examines the variable ways in which people used mobile ICTs, and the way this affected their experience of work.

\subsection{The Best and Worst Aspects of Technology-dependent Homeworking}

Data is now presented on interviewee's experiences through considering what they regarded as the most positive and negative features of their work. The single, most positive feature of work identified by interviewees, which was highlighted by eleven interviewees, was the flexibility that homeworking offered to allow the balancing of work and non-work commitments. Overall, it should be noted that more positive than negative features of homeworking were identified by the participants. Thus, the most significant negative feature of their work, an issue raised by half of the interviewees, was that their work can create a sense of social isolation, through the limited opportunities for social interaction that they often experience.

As theory on homeworking would suggest, the spatio-temporal flexibility that homeworking provided interviewees was regarded as the most positive feature of their work. For some this was simply related to having the autonomy to organize their own work schedules, with one interviewee talking about the benefit of, 'being your own boss, being able to structure and manage your own time', (5TC). Most interviewees went beyond such statements and outlined the spatio-temporal flexibility that resulted from such autonomy as being a major positive aspect of their work. For example, one interview talking primarily about temporal flexibility said,

'it's flexible work. I can start at 5 o'clock in the morning and I can be finished by 10 o'clock, so I can have a couple of hours to myself to do what I want to do. ... I haven't got to sit around and wait to start work at 9 o'clock. I can get started early or if I've got only one job and I need to go out, I can start it 3 or 4 o'clock in the afternoon', (4SJ). 
Other interviewees also made reference to how the spatial flexibility they had allowed them to balance work commitments with other types of domestic commitment such as shopping. Thus one London-based interviewee said,

II enjoy being able to slip out and hang my washing out, come back in. I can pop out to Brent Cross Shopping Centre if I need to for an hour, back again and nobody has particularly missed me', (12MB).

As suggested by the quote above, one of the key benefits of the levels of flexibility and autonomy experienced by these homeworkers was that it allowed people a significant amount of scope to balance work and non-work commitments. One of the most common types of non-work commitment that was mentioned by all interviewees who had children, was childcare, with many interviewees typically arguing that being a homeworker helps in balancing work and care responsibilities. Thus, one interviewee said,

'it's the flexibility of it [work] and I'm here for my daughter and it doesn't matter if she's sick, it doesn't matter if she's on school holiday. I haven't got to panic about childcare or paying it or... That is absolutely fantastic', (4SJ).

In general terms, the homeworkers that were interviewed were broadly happy with their work, and, as a consequence, as outlined above, the number of negative comments made about work were significantly fewer than the number of positive comments. The single most negative aspect of their work identified by interviewees was a sense of social isolation, with half of the interview cohort identifying this as a regular negative feature of their work. A lack of opportunity to socially interact with others was identified as a problem for a number of distinct reasons, both professional and social. In relation to professional isolation, the individualized nature of people's work situation, where they were independent self-employed workers with no formal colleagues, meant there was a lack of support regarding 
problem solving, as people had no peers or managers to communicate with. For example, one interviewee said

'there are times when not having somebody to bounce things off of... you know, like when you work in a corporate environment you have other people to talk to and you kind of .... I have to come up with my own solutions all the time', (1LJ).

Another example of professional isolation related to a lack of people to communicate with when a stressful situation had been experienced. Thus, one interviewee said, 'you can have a bad time with a client and you've got no one to bounce it off, so you tend to sort of take it all in on yourself', (12BB).

Interviewees also made reference to a more general sense of social isolation, which was partly related to the fact that interaction and communication with clients was typically done via email, with it being rare for people to have to either meet clients face-to-face, or even communicate by phone to carry out their work. For example, one interviewee succinctly summarized this by saying, '99\% of the work comes via email', (5CT). Another interviewee made the same point arguing that, 'communication with the client is not the biggest part of my work. It's usually all done via email. I really don't get that many phone calls', (1LJ). This feature of their work, combined with the fact that they did not employ any other workers, and that the work tasks they undertook could be done independently without any need for collaboration or communication with client staff or any other people, meant that interviewees experience of work was very much individualized, with them working on their own, in their homes. As a consequence a number of interviewees identified the lack of opportunities to chat and socialize with other people when they were working as being a negative aspect of their work. Thus, one interviewee said,

'it can be very, very lonely because you don't get to talk to the client face to face or even on the phone most of the time ... You don't get to, you know, meet round the water 
cooler and have a natter and stuff.. the biggest negative thing is that you just don't see any other adults all day and that can be quite isolating sometimes', (9SD).

With respect to the two issues examined here, people's work status as selfemployed appears to have a more significant impact on their experience of social and professional isolation, than it does on the flexibility that homeworking provides for balancing work and non-work commitments. While the experiences of interviewees in relation to the latter topic is similar to research findings for employed, homeworkers, the lack of any colleagues to interaction with suggests they experience greater levels of social and professional isolation than employed homeworkers. The focus now shifts to examine how people's use of mobile ICTs affected their experiences of work, particularly in relation to the focal themes of having the flexibility to manage the work/non-work boundary, and experiences of social and professional isolation.

\subsection{The Use of Mobile ICTs and their Impact on People's Experience of Work}

In relation to the use of mobile ICTs the most common device that people referred to was a smartphone, which was used to access email, social media sites and work remotely, most typically when people were away from the home workplace. However, as will be outlined, other technologies were also referred to by some interviewees. The interview evidence suggests that the work-related mobile ICT use among homeworkers was widespread, as very few interviewees did not use them for their work.

In general terms the impact of mobile ICT use on people's experience of work was contradictory. Thus, while half of our interviewees identified negative issues related to their use, eight referred to positive aspects of mobile ICT use. Further, many positive and negative comments were made by the same people with only a small number of people making purely positive or negative comments. One of the key findings from the analysis of work-related mobile ICT use among interviewees was 
the diversity of perspectives adopted. Overall, four separate perspectives were identified. These will be described later, with this section starting by outlining the positive and negative impacts that mobile ICT use had on people's experiences of work.

The key benefit to interviewees of the way they used their smartphones was that they were contactable by clients via phone or email irrespective of whether they were at home or not. Thus one interviewee said,

'because the phone is a smartphone and it gets emails on it .. it goes off when I get a work email so I know that somebody's looking for something and I can check that on the phone and see what they want... I have been contacted by a client while I was shopping in Meadowhall ${ }^{1}$ one day who wanted me to do something and I managed to do it on the phone while in Meadowhall and I managed to bill for it as well, so that was great ... the phone really does give me the freedom to not have to be indoors all the time', (9SD).

Interviewees who used smartphones to access email talked of how, prior to possessing them, they typically accessed their work email on computers in their homes. The importance of email as the primary means of client-based communication meant that when they were away from home it was difficult to check for client emails, which caused concerns regarding potentially important messages that may not have been accessed immediately. Thus, the quote above highlights how that checking for work emails on their smartphones when away from home enhanced people's experience of spatio-temporal flexibility, and to some extent 'liberated' them from the confines of the home work environment. This sentiment is summarized by one interviewee as follows, 'I kind of like it when I'm, for example, outside in the sun with a couple of friends and one of my clients is calling. It gives me a great feeling', 6AJ.

${ }^{1} \mathrm{~A}$ large shopping complex. 
Further, similar positive experiences were derived from the way other technologies such as netbooks (miniature laptops) and wireless internet access provided spatiotemporal flexibility, allowing people to work when away from home. This is illustrated in the following two quotations,

'if I want to go out to lunch where they've got a Wi-Fi connection, then I can go for an early lunch when it's quiet and work there. So that does help - I don't feel so tied down ... I've had it [netbook] for about 6 weeks and it's just making a tremendous difference because I can get out and I can go to Starbucks for a cup of coffee and just get away when I'm feeling overwhelmed', (8CF).

'We have a narrowboat funny enough and I work off our narrowboat quite a bit, especially if we're away weekends or I stay some Friday nights on it and I'll take my [mobile laptop internet connection] with me', (13BJ).

As with smartphone use, the above two interviewees make clear the key benefit they derive from using these technologies in the way they did was that they provide them with a degree of spatial 'liberation' from the home work environment

However, a number of interviewees also highlighted a negative consequence that can result from accessing work-related emails on mobile devices while away from the home. This was that clients can develop an expectation that people are available all the time which may make them more likely to contact people anytime, whether during working time or not. Thus one interviewee, who was broadly negative about the impact of using mobile ICTs had on people's experience of work said, I think it [a smartphone] forces you to be 24/7 and you're forever jumping to look at your emails and you never get away from it ... I've seen other virtual assistants and all their clients that get everything to their phone and they're kind of like jumping every five minutes when something comes through and I'd hate that', (5CT). 
While the quotations so far separate the positive consequences of accessing workrelated email on mobile devices away from the home from the negative consequences, a number of interviewees expressed both sentiments virtually simultaneously. This is expressed in the following two quotations,

'I don't think they're a good thing or a bad thing. I think they can be a nuisance obviously because you're constantly looking and you just want to have a look ... Emails ... come through on the phone, so they're always with me. I do think though sometimes because I'm self-employed, even if I'm on days out, I find myself checking the email because you never know, it just might be that million pound job that someone wants me to do!', (11PM).

I've got my [smartphone], so that's picking up emails without my computer being on. So I can actually see when I am out and about if an email comes in and it looks urgent, I can choose whether or not to answer it. ... They're a pain in that you can't put them down, you get addicted to them. But on the other hand it does give you the freedom to leave the office because you can still pick up stuff and deal with it if necessary', (12MB).

Thus both these quotes highlight that accessing work emails beyond the home provided the benefit of freeing them from the home work environment while also resulting in them feeling an increased need to constantly check their mobile ICTs for work email, which could make it difficult to switch off from work. Such contradictory sentiments were expressed by five interviewees. Thus for these people, the consequences of using mobile ICTs for accessing work emails beyond the home were simultaneously positive and negative.

Before describing and summarizing the different perspectives on the work-related use of mobile ICTs identified, it is necessary to examine one final perspective, thus far not touched on. This is the perspective of the four interviewees who had chosen, at the time of being interviewed, not to make any significant use of mobile ICTs in 
their work. For these people, mobile ICTs were regarded simply as not their preferred work-related communication tool, with other means of ICT-based communication being utilized (typically email via laptop or desktop computers). The lack of use of smartphones for work by these people may have been related to the fact that at the time of the interviews (Summer 2011), smartphone adoption was only just starting to become widespread. Thus one interviewee said, 'I have a phone, but it's a dinosaur. I didn't get a cell phone until 3 years ago ... I think a lot of it has to do with where we live. We live in a rural area, everyone is online, and everyone has a computer, but people are just starting to catch up on fancier phones', $(7 H S)$.

Another interviewee made a similar comment, and also highlighted how for work, their desktop and laptop computers were the crucial work-related ICTs they depended on,

'I don't have a fancy Iphone or anything like that ... my computers, I also have a laptop, those I rely on', (3TS).

Finally, one of these four people talked about having and using a mobile phone for work, but using it more as a diary and calendar, than a communication tool, 'I use my mobile phone as a diary.. I've lots of reminders and alarms', (10BB).

Thus, these four interviewees were not necessarily strongly against using smartphones for work, it was more that, at the time of the interviews, they did not possess the most up-to-date smartphone technology, and preferred to use other types of ICT, such as desktop computers, as their primary work-related communication tool.

As outlined at the start of this section, attitudes towards the work-related use of mobile ICTs, and their impact on people's experience of work were found to be quite diverse. Overall, among the 14 interviewees, four different attitudes to, and perspectives on the use of mobile ICT's for work were identified. The most common 
perspective, adopted by five interviewees was the conflicted, or paradox perspective, where the use of mobile ICTs for work was seen to have both positive and negative aspects. The second most common perspective that was adopted, which was examined immediately above, adopted by four interviewees, was the indifferent perspective. For these people, the key ICTs utilised for work were desktop computers, or laptops, and mobile ICTs such as smartphone were not regarded as being necessary for people to undertake their work. The final two perspectives that were identifiable among interviewees were the optimistic and pessimistic perspectives, which were adopted by three and two people respectively. For those adopting these perspectives, in contrast to those adopting the conflicted or paradox perspective, the work-related use of mobile ICTs was seen as being either purely positive or purely negative. For the optimists, mobile ICTs were seen to enhance levels of spatio-temporal flexibility, and allowing people the scope to leave the home without losing contact with work. For the pessimists, the workrelated use of mobile ICTs was perceived as likely to result in the demands of work being increasingly difficult to escape from, through people feeling a need to constant respond to work-related communication, irrespective of time or place. Analysis of the characteristics of interviewees adopting these perspectives was found to be unrelated to factors such the amount of time they undertook homeworking, or whether they had children or not. Each of these perspectives is explored more fully in the discussion section which follows.

\section{Discussion}

Arguably, one of main implication of mobile ICT use by homeworkers was that the use of these technologies meant that the home ceased to be their only possible workplace. This was because the ability to access email via a smartphone or via wireless internet facilities at disparate locations meant that people no longer had to be at home to access what were regarded as potentially important emails from clients. Thus, in Halford's terms, mobile ICT use has facilitated the, 'spatial 
reconfiguration of work', (2005, p. 19). Ultimately, for the type of homeworkers examined here, while the home-based workspace may continue to be the central work-hub, using mobile ICTs for work purposes anywhere means that work can be undertaken from any location where a phone signal can be received. For officebased workers who use mobile ICTs to work extended hours at home during evenings and weekends (technology assisted supplemental work - see Derks \& Bakker 2012 and Fenner \& Renn 2010) the blurring of the work-home-boundary occurs through work intruding into the home space. In contrast, for the homeworkers examined here, the opposite happened, with the work-home boundary becoming blurred due to work escaping the home (via mobile ICTs).

The increased levels of spatio-temporal flexibility this resulted in enhanced the homeworkers' ability to balance the demands of work and non-work commitments. One of the articulated benefits of homeworking was the flexibility that it gave to people allowing them to balance their work and non-work commitments (Maruyama et al 2009, Tietze et al 2009). The findings presented here reinforce such conclusions, and suggest that working in the home provides people with opportunities to effectively balance work with childcare commitments and other home-based domestic responsibilities. However, the research data presented here suggests that one of the key positive benefits of mobile ICT use by the homeworkers was that it further enhanced existing levels of spatio-temporal flexibility through allowing people to leave the home to undertake non-work commitments (such as shopping), but still remain able to either be contactable by clients via email, or to work in a location outside of the home (with examples being given of this being done in cafes and shopping centres). In relation to understanding the experience of home-based workers this is an important insight, as studies of homeworking have typically focussed narrowly, in spatial terms, on the home. These findings suggest that, due to the ways mobile ICTs can be used, homeworkers have an increased level of spatial autonomy and flexibility, and ongoing research on home-based work requires to take greater account of this. 
A second positive consequence of the enhanced levels of spatio-temporal flexibility provided by smartphones was that this helped people to address the social isolation that they occasionally experienced. Isolation was articulated by interviewees as being one of the most negative aspects of their work. This should not be surprising as Morganson et al (2010) suggest that it represents one of the drawbacks of homeworking, and Golden et al (2008) suggest that isolation is linked to the proportion of work time spent working at home. In the present study, the homeworkers' experiences of isolation were also likely to have been due to the fact that they were self-employed, and had no peers or managers at all that they could communicate with. The enhanced levels of spatio-temporal flexibility that mobile ICT use (and smartphone use in particular) provided allowed people to socialize through getting out of the home environment, while still being able have access to email and remain contactable by clients. However, while reducing people sense of general social isolation, the way the homeworkers utilized their mobile ICTs for work did not address the type of professional isolation identified as a problem by Cooper and Kurland (2002). Again, this represents a useful addition to knowledge on the topic of isolation among home-based workers, as research on this topic has almost exclusively been focussed on employed rather than self-employed homeworkers. The significant differences which exist between employed and selfemployed homeworkers, outlined above, results in experiences of professional and social isolation being substantially different. What our results suggest is that the lack of colleagues possessed by our interviewees means that the way mobile ICTs are used to help reduce social isolation, through allowing people to leave the home while still having access to work-related communications, represents a significant positive feature of work-related mobile ICT use.

The ways in which these homeworkers used mobile ICTs is conceptualised by Nippert-Eng (1996) as 'bridging', defined as, 'objects and activities that facilitate, even encourage, mental transitions between home and work' (Nippert-Eng 1996, p. 117). This is because, the way in which they used their mobile ICTs, for example to remain contactable to clients when doing activities outside the home such as 
shopping or meeting friends, allowed them to balance these multiple commitments, and easily transition from engaging with work issues to no work issues and viceversa.

The primary negative consequence of the homeworkers mobile ICT usage was that it appeared to enhance the sense of 'anytime, anywhere' contactability that people experienced (Lal \& Dwivendi 2010, Orlikowski 2007). While mobile ICT use did not produce the extreme of $24 / 7$ 'temporal servitude' that Sarker et al (2012) refer to, there were concerns by some that mobile ICT use could create a strong desire to be constantly checking for work-related messages and emails on their phones, irrespective of time or place. Similar conclusions were reached by Mustafa and Gold (2012), who examined a similar cohort of self-employed homeworkers. They reached predominantly negative conclusions suggesting that mobile ICT use created a sense where people had become 'chained' to their work, and never felt fully able to escape the need to be available for clients, and respond quickly to any requests they provided.

Importantly, where the findings of this study differ from those of Mustafa and Gold (2012) is that when looked at holistically the consequences of the way people use mobile ICTs is contradictory, rather than simply being negative. As outlined previously, the contradictory consequences of the homeworkers' work-related mobile ICT usage patterns was visible in the fact that half of the interviewees who used mobile ICTs for work simultaneously highlighted both positive and negative issues. Further, the issues highlighted were not simply separate positive and negative issues that were unconnected, but were factors which appeared to be directly contradictory. This represents another example of paradoxical characteristics of work-related mobile ICT use (Mazmanian et al 2013). On the one hand, using mobile ICTs at locations beyond the home to access work-related email 'liberated' people from the confines of the home work environment as they were now able to access what they regarded as important messages while away from the home, rather than only having access to them via home-based computers. This was 
experienced as liberating as it allowed the homeworkers to better juggle the demands of work and non-work commitments, and also helped reduce the sense of social isolation they sometimes experienced. On the other hand, this same feature of work-related mobile ICT use simultaneously resulted in people developing a sense of imprisonment, or inescapeability, as work was becoming difficult to switch off from, due to having continuous access to work-related messages irrespective of time or location. Thus, In Arnold's (2003) terms, the homeworkers' use of mobile ICTs outside of the home domain were simultaneously liberating and enslaving.

One of the key findings here, as with Nansen et al's (2010) study of how the boundaries between work and non-work are negotiated in some Australian households where home-based working occurred, was the diversity of perspectives on work-related mobile ICT use that were identified. Thus, even with the relatively small sample size of 14 utilized here, four separate perspectives on work-related mobile ICT use were identified (conflicted, indifferent, optimists and pessimists). This diversity is arguably illustrative of the user agency that represents a key feature of what Orlikowski (2010) labelled the 'emergent process' perspective on socio-technical relations. Thus, among the interview cohort researched here, four quite different attitudes towards the work-related use of mobile ICTs were identified, as well as two different use patterns being identified (with use patterns being similar for the conflicted, optimists and pessimists, but non-existent for those adopting the indifferent perspective). These use patterns illustrate how the same technological artefact, in this case mobile ICTs, can have different meanings for, and be used in quite different ways by different users.

While the paradoxical experience of those adopting the conflicted perspective have been examined already, it is useful to consider the situation of those adopting the three other perspectives. The diversity of perspectives on mobile ICT usage, and the existence of a group of interviewees (the indifferent perspective) who do not make use of mobile ICTs may be partly related to the fact that the time when the research was done (summer 2011) represented an early stage during the adoption and use of 
smartphones, where a broad diversity of user perspectives is likely to exist. Further, those adopting the indifferent perspective may simply be 'late adopters', who are cautious about using any new technology at early stages of its adoption. As the data highlighted, these people are comfortable with the use of ICTs and make extensive use of desktop and laptop computers in their work, they have simply, thus far, not found a need to use mobile ICTs to facilitate their work.

In relation to those adopting the optimist and pessimist perspectives on workrelated mobile ICT use, these people focus on particular positive or negative consequences from mobile ICT use. A possible explanation for the adoption of these views may be the perception among people that mobile ICT use is either compatible or incompatible with their preferred strategy for managing the work/non-work boundary. Despite the agency people possess to use mobile ICTs to support different boundary management strategies (see for example Duxbury et al 2014, Golden \& Geisler 2007) it is arguable that in general terms the technological characteristics of smartphones (most fundamentally their portability, and the ability to provide email and phone-based communication functionality to people almost anywhere) are more compatible with an integrationist boundary management strategy than a segmentationist one (Richardson \& Benbunan-Fich 2011). Thus, in Duxbury et al's study, more than half of those studied were classified as 'struggling segmentors' who found it difficult to both use smartphones for work, and sustain a segmentationist boundary management strategy. If this is the case, those adopting the optimist perspective may have a preference for an integrationist boundary management strategy, while those adopting the pessimist may have a preference for a segmentationist boundary management strategy. However, the data collected in our study does not allow us to effectively identify people's boundary management preferences, thus this remains a question requiring further exploration.

In approaching the end of this article it is useful to reflect on some of its limitations. A key point to highlight, which affects the generalizability of our conclusions, is the 
importance of the role of the work/employment context in shaping the homeworkers' use of mobile ICTs and the subsequent impact of this on their experience of work. Fundamentally, the importance to the homeworkers of having access to email via mobile ICTs derived not only from the fact that they were selfemployed but also that the predominant way clients contacted them was via email. Thus, for these workers, email access was regarded as crucially important, and smartphones provided them with a means to access email beyond the home without the need for a desktop or laptop computer. While this highlights the importance of taking account of the employment/work context in the analysis of technology use, it also suggests that there may be limitations to the generalizability of the findings presented here. Other types of homeworker, such as those who are employed, may be less dependent on accessing email, and thus may use smartphones for work in quite different ways to the self-employed homeworkers examined here. Therefore it would be useful to do further research on mobile ICT use by different types of homeworker to establish how comparable their use patterns and experiences are to the workers examined here.

Finally, it would also be useful to do further research on the work-related use of smartphones by any type of worker, whether they are home-based or not. This is for two main reasons. Firstly, smartphone use is becoming increasingly widespread and is likely to be a work-related technology that increasing numbers of workers are required to use. Secondly, the differences in functionality between a smartphone and previous generations of mobile phone are quite significant. Most fundamentally, smartphones give mobile access to the internet, where social media sites and email can be utilized. It may be that these differences in functionality result in different use patterns, thus research on mobile ICT use needs to keep up-to-date with such technological developments through examining the most common and contemporary devices that workers are using.

\section{$\underline{7 . \text { References }}$}


Arnold, M. (2003). On the phenomenology of technology: the "Janus-faces" of mobile phones, Information and Organization, 13, 231-256.

Barley, S. Meyerson, D. \& Grodal, S. (2011). E-mail as a Source and Symbol of Stress. Organization Science, 22, 887-906.

Baruch, Y. (2001). The status of research on teleworking and an agenda for future research, International Journal of Management Reviews, 3, 113-129.

Berg, B. (2006). Qualitative Research Methods for the Social Sciences (6th Edition). Boston: Pearson/Allyn \& Bacon.

Cooper, C., \& Kurland, N. (2002). Telecommuting, Professional Isolation and Employee Development in Public and Private Organization', Journal of Organizational Behaviour, 23, 511-532.

Cousins, K., \& Robey, D. (2005). 'Human Agency in a Wireless World: Patterns of Technology Use in Nomadic Computing Environments', Information and Organization, 15, 151-180.

Derks, D., \& Bakker, A. (2012). Smartphone Use, Work-Home Interference, and Burnout: A Diary Study of the Role of Recovery, Applied Psychology: An International Review.

Duxbury, L., Higgins, C., Smart, R., Stevenson, M. (2014). Mobile Technology and Boundary Permeability. British Journal of Management, 25, 570-588.

Fenner G., \& Renn R. (2010). Technology-Assisted Supplemental Work and Work-toFamily Conflict: The Role of Instrumental Beliefs, Organizational Expectations and time Management, Human Relations, 63, 63-82.

Golden, A., \& Geisler, C. (2007). Work-Life Boundary and the Personal Digital Assistant, Human Relations, 60, 519-551.

Golden, T., Veiga, J. \& Dino, R. (2008). The Impact of Professional Isolation on Teleworker Job Performance and turnover Intentions: Does Time Spent teleworking, interacting face-to-face, or having access to communicationenhancing Technology Matter?'. Journal of Applied Psychology, 93, 1412-21.

Halford, S. (2005). Hybrid Workspace: Re-spatialisations of Work, Organisation and Management, New Technology, Work and Employment, 20, 19-33. 
Jarvenpaa, S., \& Lang, K. (2005), Managing the Paradoxes of Mobile Technology, Information Systems Management, 22, 7-23.

Kreiner, G., Hollenbse, E., \& Sheep, M. (2009). Balancing Borders and Bridges:

Negotiating the Work-Home Interface via Boundary Work Tactics, Academy of Management Journal, 52, 704-730.

Lal, B., \& Dwivendi, Y. (2010). Investigating homeworkers' Inclination to Remain Connected to work 'anytime, anywhere' via mobile phones, Journal of Enterprise Information Management, 23, 759-774.

MacCormick, J., Dery, K. \& Kolb, D. (2012). Engaged or Just Connected? Smartphones and Employee Engagement. Organizational Dynamics, 41, 194-201.

Mann, S., \& Holdsworth, L. (2003). The Psychological Impact of Teleworking: Stress, Emotions and Health, New Technology, Work and Employment, 18, 196-211. Maruyama, T., Hopkinson, P., \& James, P. (2009). A Multivariate Analysis of WorkLife Balance Outcomes from a Large-scale Telework Programme, New Technology, Work and Employment, 24, 76-88.

Matusik, S. \& Mickel, A. (2012). Embracing or Embattled by Converged Mobile Devices? Users' Experiences with a Contemporary Connectivity Technology, Human Relations, 64, 1001-1018.

Mazmanian, M., Orlikowski, W., Yates, J. (2013). The Autonomy Paradox: The Implications of Mobile Email Devices for Knowledge Professionals, Organization Science, 24, 1337 - 1357.

Morganson, V., Major, D., \& Oborn, K. (2010). Comparing Telework Locations and Traditional Work Arrangements: Differences in Work-Life Balance Support, Job Satisfaction, and Inclusion, Journal of Managerial Psychology, 25, 578-595.

Mustafa, M., \& Gold, M. (2012). 'Chained to My work?' Strategies to Manage Temporal and Physical Boundaries among Self-employed Teleworkers, Human Resource Management Journal (DOI: 10.1111/1748-8583.12009).

Nansen, B., Arnold, M., Gibbs, M. and Davis, H. (2010). Time, Space and Technology in the Working-Home: An Unsettling Nexus, New Technology, Work and Employment, 25, 136-153. 
Nippert-Eng, C. (1996). Home and Work: Negotiating Boundaries through Everyday Life. London: University of Chicago Press

Orlikowski, W. (2007). Socio-Material Practices: Exploring Technology at Work, Organization Studies, 28, 1435-1448.

Orlikowski, W. (2010). The Sociomateriality of Organisational Life: Considering Technology in Management Research, Cambridge Journal of Economics, 34, 125141.

Osnowitz, S. (2005). Managing time in Domestic space: Home-based Contractors and Household Work, Gender and Society, 19, 83-103.

Richardson, K. \& Benbunan-Fich, R. (2011). Examining the Antecedents of Work Connectivity Behaviour During Non-work time. Information and Organization, 21, 142-160.

Sarker, S., Xiao, X., Sarker, S. \&, Ahuja, M. (2012). Managing Employees' Use of Mobile Technologies to Minimize Work-Life Balance Impacts, MIS Quarterly Executive, 11, 143-157.

Tennakoon, K.L., da Silveira, G. \& Taras, D. (2013). Drivers of Context-Specific ICT Use Across Work and Nonwork Domains: A Boundary Theory Perspective, Information and Organization, 23, 107-128.

Tietze, S., Musson, G. (2005). Recasting the Home-Work Relationship: A Case of Mutual Adjustment?, Organization Studies 26, 1331-1352.

Tietze, S., Musson, G., Scurry, T. (2009). Homebased Work: A Review of Research into Themes, Directions and Implications, Personnel Review, 38, 585-604.

Wajcman, J., Bittman, M., \& Brown, J. (2008). Families Without Borders: Mobile Phones, Connectedness and Work-Home Divisions, Sociology, 42, 635-652. 
Table 1: Interviewee Details

\begin{tabular}{|c|c|c|c|}
\hline No & Pseudonym & $\begin{array}{l}\text { Amount of time per week } \\
\text { as a VA }\end{array}$ & $\begin{array}{l}\text { Age, Marital Status, } \\
\text { Children }\end{array}$ \\
\hline 1 & LJ & Full time & $\begin{array}{l}\text { Age: } 40 \text { s, no children, } \\
\text { lives with spouse }\end{array}$ \\
\hline 2 & BJ & Full time & $\begin{array}{l}\text { Age: late 40s, lives with } \\
\text { spouse and adult child }\end{array}$ \\
\hline 3 & TS & Full Time & $\begin{array}{l}\text { Age: no children, lives } \\
\text { alone. }\end{array}$ \\
\hline 4 & SJ & Part time & $\begin{array}{l}\text { Age: } 40 \text { s, } 1 \text { child (under } \\
\text { 10), lives with spouse }\end{array}$ \\
\hline 5 & CT & Full time & $\begin{array}{l}\text { Age: late 30s, no } \\
\text { children, lives with } \\
\text { spouse }\end{array}$ \\
\hline 6 & $\mathrm{AJ}$ & Full time & $\begin{array}{l}\text { Age: early 30s, no } \\
\text { children, lives with } \\
\text { spouse }\end{array}$ \\
\hline 7 & $\mathrm{HS}$ & Part Time & $\begin{array}{l}\text { Age: } 40 \text { s, one child } \\
\text { (under } 10 \text { ), lives with } \\
\text { spouse }\end{array}$ \\
\hline 8 & FC & Half Time & $\begin{array}{l}\text { Age: } 50 \text { s, no children, } \\
\text { lives alone. }\end{array}$ \\
\hline 9 & SD & Full time & $\begin{array}{l}\text { Age: early 40s, two } \\
\text { children (one teenager } \\
\text { and one under } 5 \text { ), lives } \\
\text { with spouse }\end{array}$ \\
\hline 10 & BB & Half time & $\begin{array}{l}\text { Age: mid 40s, two } \\
\text { children (both } \\
\text { teenagers), lives with }\end{array}$ \\
\hline
\end{tabular}




\begin{tabular}{|l|l|l|l|}
\hline 11 & MP & Half time & children only. \\
\hline 12 & BM & Part time & $\begin{array}{l}\text { Age: late 30s, one child } \\
\text { (under 5), lives with } \\
\text { spouse }\end{array}$ \\
\hline 13 & JB & Part time & $\begin{array}{l}\text { Age: 50s, no children, } \\
\text { lives with spouse. }\end{array}$ \\
\hline 14 & DJ & Full time & $\begin{array}{l}\text { Age: late 40s, one adult } \\
\text { child, lives with spouse } \\
\text { and child. }\end{array}$ \\
& & & $\begin{array}{l}\text { Age: } \text { mid 30s, no children, } \\
\text { lives with spouse. }\end{array}$ \\
\hline
\end{tabular}

